upper buccal, is produced by rotation about the two mandibular condyles alternately. Rotation about the condyles occurs, to varying degrees, throughout the Primates down to Tupaia notwithstanding differences in teeth shape. In man, where there has been roduction in size of jaw, reduction of prognathism and change in jaw shape, jaw movement and the relations between cusps remain basically the same as in apes. Malocclusion is found throughout the Primates, and most frequently in those where the cusps of the posterior teeth are low and where it interferes least with function; incidence is higher and the degree more severe in animals raised in captivity. Man has the highest incidence of malocclusion, though there is marked variation between races, and indeed sometimes between small local populations. While severe malocelusion is also observed in many Primate species, it is particularly frequent in civilized man. This may be due to environmental influences on bone growth; to intermixture of populations, giving rise to incongruities of parts of the skull or size discrepancies between teeth and jaw; or to the greater likelihood of survival of individuals with severe malocclusion.

Dr. A. A. Dahlberg (Chicago) pointed out that the present minimizing of the importance of teeth in Western peoples, the reliance on foods prepared to require little mastication and on artificial substitutes for teeth, tended to lead to underestimation of their importance under primitive conditions. The dentition of American Indian peoples, whose morphological and metrical features were reviewed, shows considerable heterogeneity from group to group. He suggested that the observed differences could provide olues to the adaptive significance of variations in dental detail. Primitive diets containing considerable abrasive material led to early obliteration of crown patterns, which, it could be argued, were therefore of littlo selective significance; yet the experimental study of tooth wear showed that the tooth volume expenditure per calorie derived from a given food varies considerably with the texture and other properties of the food and with morphological details of the dentition. In primitive man subject to marginal availability of food, containing, moreover, appreciable indigestible matter, slight dental variations could well have affected survival.

Mr. D. Goose (Liverpool) reviewed some recent applications of metrical techniques. He illustrated the point, that in some dental studies the only approach available lay in measurement, by reference to problems of identification of fossil specimens; of differences in tooth size and shape between races; and of changes in jaw size, contrasting with the absence of change in tooth size, in the inhabitants of Britain since Romano-British times. Miss V. M. Carbonnell (London) reported variations in incidence and distribution of the shovel shape of incisors in Old World populations, pointing out that the decline in frequency in civilized man was compatible with the view that the function of this feature was to strengthen the incisor. Dr. V. Alexander directed attention to the elevated frequencies of double-rooted lower canines in European populations by comparison with nonEuropean. This phenomenon he interpreted as resulting from a forward extension of the morpho. genetic field responsible for the formation of more than one root in the cheek teeth.

Age assessment by dentition was discussed by Dr. A. E. W. Miles (London). Several newly developed methods allow the age of an infant to be estimated with a high degree of accuracy. In young infants when the neonatal growth line can be discerned. counting from it the number of cross-striations of the enamel prisms, or measuring the thickness of the deciduous dentine, gives estimates correct within weeks. Error increases with the age of the individual, and other dental details, for example, length of trans. lucency of the root apex, or combinations of these. give better results. At later ages erown wear, which progresses at a fairly constant rate for each tooth, allows the functional age of a tooth to be assessed. Of about 150 Saxon skulls, in 26 the age could be estimated from the state of the immature dentition, and these provide a basis for assessing the rate of crown attrition. The third molars wear slightly more slowly than the second, and these again more slowly than the first permanent molars. By comparison of the amount of wear on a number of teeth, age of adults up to about 45-50 years old can be assessed. The method applied to the whole Saxon series shows the average age at death in this population to have been about 31 years.

With Prof. C. F. Ballard and P. O. Pedersen in the chair respectively in the morning and afternoon sessions the meeting proceeded smoothly. Most members of the audience found much that was new in most of the papers. There were, of courss, topics of current interest which did not appear in the programme; for example, variations in dental growth among different human populations, secular and regional variations in dental disease incidence, the relation between chewing habits and dental structure. Yet there is a limit to what can be covered in a single day's discussion, and the organizer, Dr. D. R. Brothwell, is to be congratulated on a stimulating programme as representative of present trends in dental anthropology as time would allow.

D. F. ROBRrTS

\title{
THE VICKERS GROUP RESEARCH ESTABLISHMENT
}

L ORD HAILSHAM, Minister for Science, visited the Vickers Group Research Establishment in Sunninghill, near Ascot, on December 4, when he met the Boards of Directors of Vickers, Ltd., and Vickers Research, Ltd., and members of the Research Establishment. During his visit he was shown examples of the present lines of work, new research tools and some novel products which are results of the research work. This Establishment is the centre of the research organization of the Vickers Group of companies and is operated by the Research Company. It carries out both fundamental and applied research, the results of which are used by the companies of the Group when they are likely to yield profitable new products or processes. The present work inoludes. among others, medical, chemical, hydraulio and electron physics investigations.

The medical work is based on a combination of the disciplines of the biological and physical sciences. It is concentrated on the respiratory and circu- 
latory systems, some aspects of human biology (especially those created by unusual environments) and some aspects of social medicine related to the design and equipment of hospitals. Comparative measurements of the mechanics of respiration have shown distinctive differences between conscious, adult Equidae and certain other species of domestic mammals, birds and man.

Among the now medical equipment shown were transparent mobile oxygen chambers in which patients can be troated at pressures up to $60 \mathrm{lb}$./sq. in., and in which human beings have been shown capable of tolerating rates of rise of ambient pressure as high as $5 \mathrm{lb} . / \mathrm{sq}$. in. per min. without subjective sensation. These chambers are used to treat industrial gas poisoning, oxygen lack in the newly born and other conditions in which hypoxia, central or local, is a crucial factor. A new lightweight, 'positive pressure' breathing set for the fire and rescue services and similar examples of fabric engineering devices for use in medicine and nursing were demonstrated.

Chemical investigations are concentrated mainly on the kineties of the pyrolysis and the oxidation of hydrocarbons at high temperatures, and on the use of fluidized beds both as chemical reactors and heat exchangers. A fully instrumented shock-tube built for these kinetic investigations, parts of a second shock-tube now being built and a model of a fluidized bed were shown. A great deal of work is being done at present on the reconciliation of different methods of measuring temperatures in the reaction. zone of the shock tube.

The hydraulic work is concentrated on power transmission systems and servo mechanisms. As examples of this work a new type of flow control valvo and a vibrator capable of shaking a load of
$450 \mathrm{lb}$. (a man and all his equipment) were demonstrated. The essential element of the flow-control valve is a nylon-fibre glass sleeve which permits rates of flow sensibly independent of down-stream pressure without necessitating close manufacturing tolerances. The vibrator was built for human biological research. It has a maximum displacement in the vertical plane of about $2 \mathrm{ft}$. and a frequency response of 20 cycles per sec. It is used to study the effects of random, vertical accelerations, similar to those encountered in high-speed flight at low altitudes. A profound difference has been found between the effect on the human body of eyclic and random vibration.

The electron physics work is principally concerned with atomic particle accelerators, especially the linear accelerator, as an intense source of high-energy electrons, positrons and X-rays. As already reported in Nature ${ }^{1}$ (and afterwards discussed by other workers ${ }^{2}$ ), it has been shown that pulse break-up can be prevented and beam currents can be increased by the use of accelerator structures which prevent the propagation of the backward wave mode.

A sealed-off 6-million-volt X-ray tube (basically a linear electron accelerator working on the $X$-band), similar to others now incorporated in operational radiographic and radiotherapeutic $\mathrm{X}$-ray machines, was shown. A radio-frequency particle separator (to be used with the CERN $30-\mathrm{GeV}$. synchrotron) for the separation of particles of almost equal momentum was also shown. This separator is operated at 2,856 megacycles per sec. and delivers 20-MW. pulses of $10 \mu$ sec. duration to each of the cavities.

\section{F. BAREFord}

Kelliher, M. G., and Beadle, R., Nature, 187, 1099 (1960).

${ }^{2}$ Crowley-Milling, M. C., Jarvis, T. R., Miller, C. W., and Saxon, G., Nature, 191, 483 (1961).

\section{THE MEDICAL RESEARCH COUNCIL}

$\mathrm{R}$ EADERS of the successive reports of the Medical Research Council have learned, especially during the past few years, to look on these reports as guides to progress in the numerous branches of medical science which the Council nowadays undertakes. The latest report* maintains the high quality of its predecessors.

It follows in general the plan of previous reports, but unhappily has to record the deaths of Sir Geoffrey Jefferson, whose great contributions to surgery, especially to that of the brain, are so well known that they need no comment here, and of Prof. T. R. Elliott, who was the last surviving member of tho Medical Research Committee which preceded the present Council; it was Elliott who advised the appointment of Sir Walter Fletchor as the original secretary of the Medical Research Committee and so made possible the great services which Sir Walter later gavo to medical research. This report also records the death of $\mathrm{Dr}$. James Reid, director of the recently established Clinical Chemotherapy Research Unit at Glasgow. It also pays a welldeserved tribute to the work of Lord Limerick, who retired from its chairmanship in November 1960. During his chairmanship great advances were made. In 1953 the Council set up its Clinical Research

* Committee of Privy Council for Medical Research. Report of the Medical Research Council for the year 1959-60. (Cmnd. 1422.) Pp. viii + 326. (London: H.M.S.O., 1961.) 15s, 6d. net.
Board, which has now been succeeded by the Clinical Research Centre to be established in the proposed new District Hospital at Northwick Park, Middlesex, and also during the chairmanship of Lord Limerick, the Tropical Medicine Research Board was established in 1960 to succeed the former Colonial Medical Research Committee.

Much of the report is necessarily occupied with the full details it gives of the administrative structure of the Council, together with summaries of the work of its numerous research units, details of its external staff, and of the institutions and research workers it supports by block grants, and of research work helped by these grants, and also of the numerous personnel employed by the Council, and of its publications. This year the report does not give, as its predecessors did, details of the work of the Public Health Laboratory Service, because this Service now operates under the now Public Health Laboratory Service Board, the chairman of which is Sir Landsborough Thomson. Thus, this new Board will benefit from the wide experience gained by Sir Landsborough during the years when he served the Medical Research Council.

An outstanding feature of the Council's reports during the past few years has been the section entitled "Some Aspects of Medical Research", in which certain aspects of the Council's work are solected each year for special comment and summary. This section is, as many readers will know, published 